\title{
Breaking Bad: An Assessment of Ophthalmologists' Interpersonal Skills and Training on Delivering Bad News
}

\author{
Nicole M. Fuerst, MD ${ }^{1} \quad$ Jessica S. Watson, MD $^{2} \quad$ Nicole A. Langelier, MD ${ }^{3}$ R. Egen Atkinson, MD, MBA \\ Gui-Shuang Ying, $\mathrm{PhD}^{1}$ Wei Pan, $\mathrm{MS}^{1}$ Vincent Palladino, $\mathrm{BA}^{1} \quad$ Collin Russell, $\mathrm{BS}^{1}$ \\ Vanessa Lin, MS, DO ${ }^{1}$ Paul J. Tapino, MD ${ }^{1} \quad$ Joan M. O’Brien, $\mathrm{MD}^{1}$
}

\footnotetext{
${ }^{1}$ Department of Ophthalmology, Scheie Eye Institute, University of Pennsylvania, Philadelphia, Pennsylvania

2 Department of Ophthalmology, University of lowa, lowa City, lowa

${ }^{3}$ Department of Ophthalmology, Duke Eye Center, Duke University, Durham, North Carolina
}

Address for correspondence Joan M. O'Brien, MD, Department of Ophthalmology, Scheie Eye Institute, University of Pennsylvania, 51 N. 39th Street, Philadelphia, PA 19104

(e-mail: joan.obrien@uphs.upenn.edu).

J Acad Ophthalmol 2018;10:e83-e91.

\begin{abstract}
Keywords

- breaking bad news

- core competencies

- medical education

Purpose This article aims to assess ophthalmologists' practice patterns, experiences, and self-perceived skills when delivering bad news to patients and to compare this to patients' experience and preferences in receiving bad news from ophthalmologists. Design/Methods This is a prospective cross-sectional survey study of two populations: (1) Attending ophthalmologists and current ophthalmologists-in-training $(N=202)$ at accredited ophthalmology residency programs in the United States and Canada. (2) Patients $(N=151) 18$ years of age and older at a single academic center who had received bad news from their ophthalmologist. An e-mail was sent to ophthalmology department chairs and resident program directors requesting that they distribute an online survey to their faculty, fellows, and residents. Patients were recruited from the clinics at an academic center and completed a self-administered survey before their scheduled appointments. Both populations were surveyed on their experience in breaking and receiving bad news, respectively. Questions were rated on a standard five-point Likert scale, and mean score was calculated for statistical comparison. The primary outcome variable was the quantitative rating (Likert scale 1-5) of physicians' communication skills when delivering bad news from physicians and patients' responses.

Results Patients rated their physicians higher than physicians rated themselves with regard to ability to deliver bad news (mean score of 4.23 vs. 3.48, $p<0.01$ ). Multivariate analysis showed frequent delivery of bad news (mean score of 3.66 for once per day, 3.53 for per week, 3.40 for once per month, and 3.22 for once per year, linear trend; $p=0.004$ ) and years of practice were associated with better selfperceived ability to deliver bad news (mean score of 3.75 for $\geq 15$ years, 3.48 for $<15$ years, and 3.30 for residents/fellows, linear trend; $p<0.001$ ). Having received formal training in breaking bad news was associated with better perceived ability score,
\end{abstract}

received

February 19, 2018

accepted

June 4,2018
DOI https://doi.org/

10.1055/s-0038-1667051. ISSN 2475-4757.
Copyright $\odot 2018$ by Thieme Medical Publishers, Inc., 333 Seventh Avenue, New York, NY 10001, USA. Tel: +1(212) 584-4662.
License terms

(c) (1) $\ominus$ (\$) 
yet not statistically significant (3.51 vs. 3.39, $p=0.31$ ). Most patients $(97.5 \%)$ and physicians $(92.1 \%$ ) believe delivering bad news can be taught.

Conclusion Physicians and patients agree that skills of delivering bad news can be learned. Patients are less critical of their physicians' ability to deliver bad news than physicians are themselves. Further study of best methods to deliver bad news is clearly indicated for the field of ophthalmology.

In public opinion polls conducted over the past 40 years, Americans have consistently ranked vision loss as second only to cancer among their greatest health fears. ${ }^{1}$ Therefore, receiving the diagnosis of a blinding eye condition can be considered to be "bad news," which Alelwani and Ahmed defined as "any information transmitted to patients or their families that directly or indirectly involves a negative change in their lives." ${ }^{2}$ The oncology literature has demonstrated that the manner in which bad news is given to patients can have a significant effect on patients' well-being, perceptions of their disease, and relationship with their physician. ${ }^{3}$ Ineffective delivery of bad news can increase patient anxiety and risk of depression. ${ }^{4}$

While there are numerous studies on "breaking bad news" in the oncology literature including evaluation of patient's preferences, physician's communication skills, the effect and quality of physician training in delivering bad news, as well as the long-term effects on the patients of the physician's communication skills, ${ }^{5-7}$ there is very limited literature in ophthalmology related to physician's communication skills when breaking bad news to patients. ${ }^{8,9}$ These small studies in ophthalmology have shown that ophthalmologists agree that a formal training program would be beneficial ${ }^{8,9}$ and that training may increase the confidence level of ophthalmologists in their ability to deliver bad news. ${ }^{9}$ Still, there are no studies to date in ophthalmology which have addressed patient's preferences when receiving bad news, assessed the patient's experience when receiving bad news, evaluated the extent of ophthalmologist training in breaking bad news, or commented on how any of these measures vary with patient demographics (e.g., ethnicity) or physician characteristics (e.g., level of training, practice setting). Hence, the purpose of the present study is to answer these questions.

\section{Methods}

The study was approved by the Institutional Review Board at the University of Pennsylvania, was HIPAA compliant, and informed consent was obtained from all participants before their participation in the study. This study also adhered to the tenets of the Declaration of Helsinki. This study recruited two populations of subjects: (1) ophthalmologists and ophthalmologists-in-training and (2) patients who had received bad news from their ophthalmologist.

\section{Physician Recruitment and Survey}

We were granted approval from the Association of University Professors of Ophthalmology (AUPO) to obtain the listserv of 282 department chairs and program directors at accredited ophthalmology residency programs in the United States and Canada. An e-mail was sent from the chair of our department to the department chairs at accredited programs requesting that they disseminate our online survey to their faculty. A similar e-mail from our department's program director was sent to the program directors at accredited ophthalmology residency programs requesting that they disseminate our online survey to their residents and fellows. A reminder e-mail was sent to department chairs and program directors 4 months after the initial e-mail. We do not know how many of the department chairs or program directors ultimately disseminated the survey to their faculty and residents, and thus, a response rate could not be calculated.

Physicians received an invitation via email with a link to complete an electronic survey administered by Survey Monkey. The 21-item questionnaire asked about physicians' perspective on various aspects of breaking bad news in ophthalmology including frequency of delivering bad news, self-perceived ability, comfort level, methods employed to break bad news, previous training in breaking bad news, the importance of breaking bad news, and whether or not breaking bad news can be taught. Physicians were also asked to answer questions regarding demographic data including age, race, sex, current level of training/practice, focus, and type of practice. Questions were either in the yes/no format, "check all that apply," or rated on a Likert scale of 1 to 5 ( $1=$ not at all, $5=$ absolutely $)$.

\section{Patient Recruitment and Survey}

Patients at least 18 years of age or older were recruited from the ophthalmology patient populations at the Scheie Eye Institute or the Perelman Center for Advanced Medicine at the University of Pennsylvania from June 2015 through February 2016. Patients who remembered receiving bad news from their ophthalmologist and were present at the time of data collection were asked to participate and sign informed consent for the study.

The 27-question survey was self-administered by patients. If patients were not able to read or complete the survey, study personnel other than the treating physicians recorded the patient's responses. In addition to demographic data (age, race, sex, level of education), patients were surveyed on various facets of receiving bad news including the nature of the bad news they received, how well their physician communicated this bad news, how empathic their physician was, how well they understood their physician's 
message, how helpful different methods employed by their physician were in helping them to understand and/or cope with the bad news, and whether breaking bad news can be taught. Additionally, they were asked how much information they desired on their condition, whether they wanted to hear about possible treatments, what makes a doctor a good doctor, their preferences for bedside manner, and other methods that doctors can employ to help their patients cope with bad news. Questions were either in the yes/no format, "check all that apply," or rated on a Likert scale of 1 to 5 ( $1=$ not at all, $5=$ absolutely $)$.

\section{Statistical Methods}

Descriptive analysis was performed for the responses of each survey question. Continuous data (age, Likert score, etc.) were summarized using mean, standard deviation, and quantiles. Categorical responses were summarized by proportions. Two-group $t$-test was used for comparing means (i.e., quantitative rating of communication skills) and chisquare tests or Fisher's exact tests for comparing proportions (i.e., proportion of good or bad communication skills for breaking bad news) between comparison groups. The univariate and multivariate linear regression analyses were performed to evaluate the factors associated with ability to break bad news. The factors associated with a $p$-value $<0.20$ in the univariate analysis were included in a multivariate regression model so that the independent effect of each factor could be assessed. The final multivariate model was created by applying a backward variable selection procedure that retained only those factors with a $p \leq$ 0.05 , with the exception of variable on "ever received training in breaking bad news," which was included in the final multivariate model due to our particular interest in this variable. The test of linear trend was used for evaluating the association of years of practice and frequency of delivering bad news with ability to break bad news. Two-sided $p<0.05$ is considered to be statistically significant. All statistical analyses were performed in SAS v9.3 (SAS Institute Inc., Cary, NC).

\section{Results}

\section{Characteristics of Study Subjects}

A total of 202 ophthalmologists and ophthalmologists-intraining and 151 patients completed the questionnaire, and their demographic characteristics are shown in - Table 1. For physicians, mean age \pm standard deviation (SD) was $41 \pm 14$ years (range: $25-84$ years), 72 (35.6\%) were female, and the majority were white $(74.2 \%)$. Ninety-two (45.5\%) were still in residency or fellowship training at the time of the study. The majority (99.5\%) were practicing in an academic setting and the most common field of practice was comprehensive surgical ophthalmology (40.1\%).

For patients, the mean age ( \pm SD) was $60 \pm 15$ years, half of them were female, $52 \%$ were white, $45 \%$ were black, and more than half of the patients (66.2\%) had completed at least a bachelor's degree.

\section{Physician's and Patient's Experience in Breaking and Receiving Bad News}

As shown in - Table 2, 142 physicians (70.3\%) had previously received formal training in breaking bad news, and this training was most likely to occur during medical school (62.9\% of respondents). Of the current residents, $97.9 \%$ had already received formal training, and physicians who were in practice longer were less likely to have received training in breaking bad news ( - Fig. 1, $p<0.001$ ). Fifty-five percent of physicians, on average, would estimate that they deliver bad news to their patients at least once per week. When physicians were asked their comfort level when delivering bad news on the 5 -point Likert scale ( $1=$ not at all comfortable, $5=$ completely comfortable), the mean score $( \pm S D)$ was $3.4 \pm 0.7$, with $8.4 \%$ of physicians rating themselves "completely comfortable," 32.7\% "comfortable," 53.0\% "somewhat comfortable," and 5.9\% "not comfortable" in delivering bad news (-Table 2).

When physicians were asked to rate their ability to deliver bad news, the mean score ( \pm SD) was $3.5 \pm 0.6$ with $54.5 \%$ rating themselves as "somewhat skilled" and $39.1 \%$ as "very skilled." When physicians were asked to rate the skill of all ophthalmologists in the United States in their ability to deliver bad news, the mean score $( \pm \mathrm{SD})$ was $2.9 \pm 0.5$ with $71.3 \%$ answering they believed most ophthalmologists to be "somewhat skilled."

Patients rated their physicians higher than physicians rated themselves with regard to ability to break bad news (score of $4.2 \pm 1.2$ vs. $3.5 \pm 0.6, p<0.01$ ). Similarly, physicians felt that patients understood them less when delivering bad news compared with patient's perceptions of how well they understood their physician when receiving bad news ( $3.6 \pm 0.6$ vs. $4.3 \pm 1.1, p<0.001$ ). The majority of physicians $(97.5 \%)$ and patients $(92.1 \%)$ believed that delivering bad news could be taught, and $68.3 \%$ of physicians felt that ophthalmology residency programs should be required to teach techniques in breaking bad news.

The strategies employed to help patients cope with bad news are shown in - Table 2. Of the patients surveyed, $66.2 \%$ said that they would find talking to a technician or other staff member helpful, and 55\% said that they would find speaking to another patient with the same eye problem helpful. In contrast, only $12.4 \%$ of physicians offered patients the ability to speak with their technician or other staff member, and only $21.3 \%$ of physicians put patients in contact with other patients with the same eye problem. Most patients (78.8\%) stated that they would like to receive more information on their condition when receiving bad news. Additionally, 86.8\% of patients stated that they would like to receive a brochure on their eye problem and $72.2 \%$ said that they would like to be shown information online.

\section{Factors Associated with Physician's Self-Perceived Ability to Deliver Bad News}

In univariate analysis (-Table $\mathbf{3}$ ), age was significantly associated with self-perceived ability to deliver bad news with older physicians rating their ability higher than younger physicians $(p=0.009)$. Sex and race were not significantly 
Table 1 Characteristics of study physicians and patients

\begin{tabular}{|c|c|c|}
\hline $\begin{array}{l}\text { Characteristics of } \\
\text { participants }\end{array}$ & $\begin{array}{l}\text { Physicians } \\
(N=202)\end{array}$ & $\begin{array}{l}\text { Patients } \\
(N=151)\end{array}$ \\
\hline \multicolumn{3}{|l|}{ Age $(y)^{a}$} \\
\hline Mean (SD) & $41(14)$ & $60(15)$ \\
\hline Median (min, max) & $35(25,84)$ & $63(23,94)$ \\
\hline Sex: Female (\%) & $72(35.6 \%)$ & $75(49.7 \%)$ \\
\hline \multicolumn{3}{|l|}{ Race } \\
\hline White & $\begin{array}{l}141 \\
(74.2 \%)\end{array}$ & 79 (52.3\%) \\
\hline Black & $2(1.1 \%)$ & $68(45.0 \%)$ \\
\hline Asian & $35(18.4 \%)$ & $1(0.7 \%)$ \\
\hline Other & $24(11.9 \%)$ & $3(2.1 \%)$ \\
\hline \multicolumn{3}{|l|}{ Years of education } \\
\hline Some high school & & $8(5.3 \%)$ \\
\hline High school diploma & & $40(26.5 \%)$ \\
\hline Bachelor & & $56(37.1 \%)$ \\
\hline Graduate & & $44(29.1 \%)$ \\
\hline Other & & $3(2.0 \%)$ \\
\hline \multicolumn{3}{|c|}{ Current level of training or practice } \\
\hline PGY-2 & $36(17.8 \%)$ & \\
\hline PGY-3 & $19(9.4 \%)$ & \\
\hline PGY-4 & $29(14.4 \%)$ & \\
\hline $\begin{array}{l}\text { Postresidency/fellowship } \\
\text { board eligible }\end{array}$ & $4(2.0 \%)$ & \\
\hline Fellow & $8(4.0 \%)$ & \\
\hline Board certified for $<5 y$ & $20(9.9 \%)$ & \\
\hline Board certified for 5-9 y & $12(5.9 \%)$ & \\
\hline Board certified for $10-14$ y & $13(6.4 \%)$ & \\
\hline Board certified for $15-19$ y & $12(5.9 \%)$ & \\
\hline Board certified for $\geq 20 y$ & $49(24.3 \%)$ & \\
\hline \multicolumn{3}{|l|}{ Type of practice } \\
\hline Academic/University only & $\begin{array}{l}185 \\
(91.6 \%)\end{array}$ & \\
\hline $\begin{array}{l}\text { Private practice/Academic } \\
\text { mix }\end{array}$ & $16(7.9 \%)$ & \\
\hline Private practice only & $1(0.5 \%)$ & \\
\hline \multicolumn{3}{|l|}{ Field of practice } \\
\hline $\begin{array}{l}\text { Comprehensive surgical } \\
\text { ophthalmology }\end{array}$ & $81(40.1 \%)$ & \\
\hline $\begin{array}{l}\text { Comprehensive nonsurgical } \\
\text { ophthalmology }\end{array}$ & $19(9.4 \%)$ & \\
\hline Vitreoretinal surgery & $24(11.9 \%)$ & \\
\hline Cornea or refractive surgery & $15(7.4 \%)$ & \\
\hline Glaucoma & $15(7.4 \%)$ & \\
\hline $\begin{array}{l}\text { Pediatric ophthalmology/ } \\
\text { Adult strabismus }\end{array}$ & $15(7.4 \%)$ & \\
\hline Neuroophthalmology & $13(6.4 \%)$ & \\
\hline
\end{tabular}

Table 1 (Continued)

\begin{tabular}{|l|l|l|}
\hline $\begin{array}{l}\text { Characteristics of } \\
\text { participants }\end{array}$ & $\begin{array}{l}\text { Physicians } \\
(N=202)\end{array}$ & $\begin{array}{l}\text { Patients } \\
(N=151)\end{array}$ \\
\hline Medical retina & $9(4.5 \%)$ & \\
\hline $\begin{array}{l}\text { Oculoplastic and orbital } \\
\text { surgery }\end{array}$ & $7(3.5 \%)$ & \\
\hline Ocular oncology & $2(1.0 \%)$ & \\
\hline Ocular pathology & $1(0.5 \%)$ & \\
\hline Uveitis & $1(0.5 \%)$ & \\
\hline
\end{tabular}

${ }^{\mathrm{a} A g e}$ was not provided for 19 physicians.

correlated with self-perceived ability to deliver bad news $(p>0.29)$.

In both univariate and multivariate analyses that included current level of training/practice, ever received training in breaking bad news, and frequency of delivering bad news, current level of training or practice was significantly associated with self-perceived ability to deliver bad news, such that physicians who were in practice longer rated their skill higher (adjusted mean \pm standard error: resident, $3.30 \pm 0.07$; $<15$ years, $3.48 \pm 0.09 ;>15$ years, $3.75 \pm 0.09$; linear trend; $p<0.001$; - Table 3). Similarly, physicians who deliver bad news more frequently felt more skilled than physicians who deliver bad news less frequently (adjusted mean \pm standard error: $3.66 \pm 0.11$ for once per day, $3.53 \pm 0.06$ for once per week, $3.40 \pm 0.07$ for once per month, $3.22 \pm 0.14$ for once per year; linear trend; $p=0.004$ ). Physicians who had received formal training in breaking bad news had a better perceived ability score, but this was not statistically significant (adjusted mean \pm standard error: $3.51 \pm 0.06$ vs. $3.39 \pm 0.09$, $p=0.31 ;$ - Table 3 ).

\section{Patient's Preference in Receiving Bad News}

Patients' preferences for their physician's bedside manner are shown in $\mathbf{- T a b l e ~ 4}$. Females more than males preferred that their physician hold their hand or touch their arm (mean Likert score: 3.1 vs. $2.6, p=0.04$ ) and encourage them to talk about their feelings (mean Likert score: 3.8 vs. 3.4, $p=0.02$ ) when delivering bad news. Non-white patients (black, Asian, or other) more than white patients also preferred that their physician hold their hand or touch their arm (mean score: 3.3 vs. 2.5, $p<0.001$ ) and encourage them to talk about their feelings (mean score: 3.9 vs. 3.3, $p<0.001$ ). Middle-aged patients (50-64 years) were more likely to want to speak to other patients with the same eye problem compared with younger (20-49 years) and older ( $\geq 65$ years) patients (74.0, 51.5 , and $46.7 \%$, respectively, $p=0.01$ ). A larger percentage of black patients responded that they would like to be given the opportunity to talk with their family when receiving bad news $(87.7 \%$ of black patients vs. $59.7 \%$ of white patients, $p<0.001$ ). Lower level of education was significantly correlated with a patient's desire to talk to other people with the same eye problem $(71.4 \%$ of high school graduates vs. $52.8 \%$ of patients with bachelor degree vs. $46.3 \%$ of patients with a graduate degree; $p=0.04$ ). 
Breaking Bad News in Ophthalmology Fuerst et al. e87

Table 2 Patient's and physician's experience in delivering bad news

\begin{tabular}{|c|c|c|}
\hline & $\begin{array}{l}\text { Physician } \\
\text { response } \\
(n=202)\end{array}$ & $\begin{array}{l}\text { Patient } \\
\text { response } \\
(n=151)\end{array}$ \\
\hline \multicolumn{3}{|l|}{$\begin{array}{l}\text { Received training in breaking } \\
\text { bad news }\end{array}$} \\
\hline No & $60(29.7 \%)$ & \\
\hline Yes & $\begin{array}{l}142 \\
(70.3 \%)\end{array}$ & \\
\hline In medical school & $\begin{array}{l}127 \\
(62.9 \%)\end{array}$ & \\
\hline $\begin{array}{l}\text { In ophthalmology } \\
\text { residency or fellowship }\end{array}$ & $30(14.9 \%)$ & \\
\hline $\begin{array}{l}\text { After completed } \\
\text { ophthalmology training }\end{array}$ & $18(8.9 \%)$ & \\
\hline \multicolumn{3}{|c|}{$\begin{array}{l}\text { Approximately how often do you break bad news } \\
\text { to patients }\end{array}$} \\
\hline Once per day & $31(15.3 \%)$ & \\
\hline Once per week & $80(39.6 \%)$ & \\
\hline Once per month & $74(36.6 \%)$ & \\
\hline Once per year & $17(8.4 \%)$ & \\
\hline \multicolumn{3}{|c|}{$\begin{array}{l}\text { How comfortable are you with your ability to deliver bad } \\
\text { news }\end{array}$} \\
\hline Not at all comfortable & $1(0.5 \%)$ & \\
\hline Not comfortable & $11(5.4 \%)$ & \\
\hline Somewhat comfortable & $\begin{array}{l}107 \\
(53.0 \%)\end{array}$ & \\
\hline Comfortable & $66(32.7 \%)$ & \\
\hline Completely comfortable & $17(8.4 \%)$ & \\
\hline Mean Likert score (SD) & $3.4(0.7)$ & \\
\hline \multicolumn{3}{|c|}{$\begin{array}{l}\text { How would rate your/your physician's ability to deliver bad } \\
\text { news }\end{array}$} \\
\hline $\begin{array}{l}\text { Poorly skilled and } \\
\text { ineffective }\end{array}$ & $0(0 \%)$ & $8(5.3 \%)$ \\
\hline Not skilled and ineffective & $3(1.5 \%)$ & $6(4.0 \%)$ \\
\hline $\begin{array}{l}\text { Somewhat skilled and } \\
\text { effective }\end{array}$ & $\begin{array}{l}110 \\
(54.5 \%)\end{array}$ & $19(12.6 \%)$ \\
\hline Skilled and effective & 79 (39.1\%) & $26(17.2 \%)$ \\
\hline $\begin{array}{l}\text { Completely skilled and } \\
\text { effective }\end{array}$ & $10(5.0 \%)$ & $90(59.6 \%)$ \\
\hline Mean Likert score (SD) & $3.5(0.6)$ & $4.2(1.2)$ \\
\hline \multicolumn{3}{|c|}{$\begin{array}{l}\text { How well does your patient understand you/how well do you } \\
\text { understand your physician }\end{array}$} \\
\hline Not at all & $1(0.5 \%)$ & $6(4.0 \%)$ \\
\hline A little & $2(1.0 \%)$ & $4(2.6 \%)$ \\
\hline Somewhat & $87(43.1 \%)$ & 19 (12.6\%) \\
\hline Most of them & $\begin{array}{l}106 \\
(52.5 \%)\end{array}$ & $29(19.2 \%)$ \\
\hline Completely & $6(3.0 \%)$ & $92(60.9 \%)$ \\
\hline Mean Likert score (SD) & $3.6(0.6)$ & $4.3(1.1)$ \\
\hline
\end{tabular}

Table 2 (Continued)

\begin{tabular}{|c|c|c|}
\hline & $\begin{array}{l}\text { Physician } \\
\text { response } \\
(n=202)\end{array}$ & $\begin{array}{l}\text { Patient } \\
\text { response } \\
(n=151)\end{array}$ \\
\hline \multicolumn{3}{|c|}{$\begin{array}{l}\text { How would you rate the average ability of all ophthalmol- } \\
\text { ogists in the United States to deliver bad news }\end{array}$} \\
\hline Poorly skilled & $0(0 \%)$ & \\
\hline Not skilled & 39 (19.3\%) & \\
\hline Somewhat & $\begin{array}{l}144 \\
(71.3 \%)\end{array}$ & \\
\hline Skilled & $19(9.4 \%)$ & \\
\hline Highly skilled & $0(0 \%)$ & \\
\hline Mean Likert score (SD) & $2.9(0.5)$ & \\
\hline $\begin{array}{l}\text { Can delivering bad news be } \\
\text { taught: Yes (\%) }\end{array}$ & $\begin{array}{l}197 \\
(97.5 \%)\end{array}$ & $\begin{array}{l}139 \\
(92.1 \%)\end{array}$ \\
\hline $\begin{array}{l}\text { Should ophthalmology resi- } \\
\text { dency program be required to } \\
\text { teach techniques in breaking } \\
\text { bad news: Yes (\%) }\end{array}$ & $\begin{array}{l}138 \\
(68.3 \%)\end{array}$ & \\
\hline \multicolumn{3}{|c|}{$\begin{array}{l}\text { Approaches employed/Helpful approaches used by your } \\
\text { physician to help you cope with bad news }\end{array}$} \\
\hline Talking with doctor & 200 (99\%) & $\begin{array}{l}147 \\
(97.4 \%)\end{array}$ \\
\hline $\begin{array}{l}\text { Talking with technician or } \\
\text { other staff }\end{array}$ & 25 (12.4\%) & $\begin{array}{l}100 \\
(66.2 \%)\end{array}$ \\
\hline $\begin{array}{l}\text { Talking with other patients } \\
\text { with same eye problem }\end{array}$ & $43(21.3 \%)$ & $83(55.0 \%)$ \\
\hline Talking with family & $N A^{a}$ & $\begin{array}{l}104 \\
(68.9 \%)\end{array}$ \\
\hline Information brochure & $\begin{array}{l}118 \\
(58.4 \%)\end{array}$ & $\begin{array}{l}131 \\
(86.8 \%)\end{array}$ \\
\hline Information online & $\begin{array}{l}104 \\
(51.5 \%)\end{array}$ & $\begin{array}{l}109 \\
(72.2 \%)\end{array}$ \\
\hline
\end{tabular}

a"Talking with family" is not an option in the physician survey.

\section{Discussion}

Nonophthalmology literature has revealed that there should be a greater emphasis on communication, especially when breaking bad news to patients. In fact, studies have shown that doctor-patient communication is the principal determinant of happiness and satisfaction scores for patients. ${ }^{10}$ The Accreditation Council for Graduate Medical Education (ACGME) and the American Board of Ophthalmology (ABO), in their "Ophthalmology Milestone Project," support this notion and have named "interpersonal and communication skills" as one of the core competences for resident education. In the Milestone Project, one of the facets that residents are to be evaluated on as they go through training is their ability to use "appropriate techniques in breaking bad news."11 However, there is a paucity of literature on how to effectively communicate bad news in the field of ophthalmology, and there is a clear need for a structured approach to educating and evaluating ophthalmologists in this vital area. ${ }^{12}$ 


\section{Physician Response}

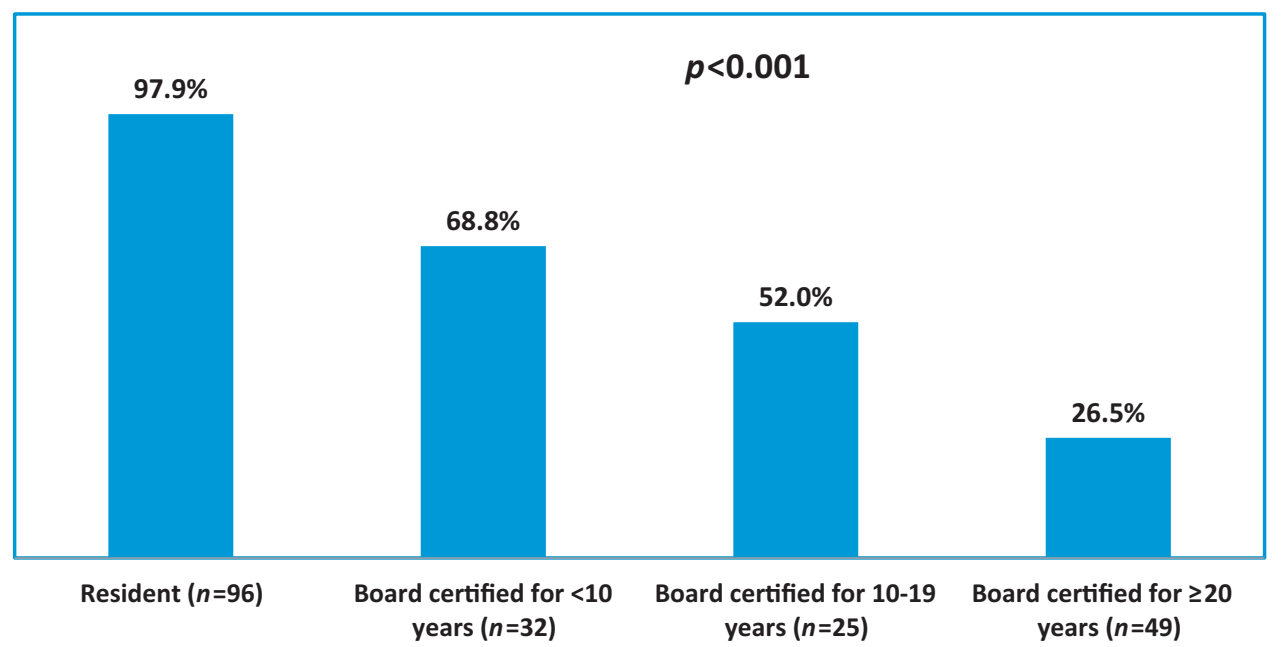

Fig. 1 Percent of ever received training in breaking bad news by level of training and practice.

Although few people enjoy disclosing bad news, physicians and other healthcare professionals inevitably have to perform this task. While some people are naturally more empathetic than others, breaking bad news is a skill that can improve with practice. ${ }^{13}$ Our study findings support this idea since the results indicate that physician comfort and selfperceived ability to break bad news increase significantly by years in practice and frequency of delivering bad news.

Both physicians and patients in our study agreed that formal training for physicians in breaking bad news is important for patient care and the majority believed it to be a teachable skill. Similarly, Zakrzewski et al reported that 99\% of ophthalmologists in the Canadian Ophthalmologic Society believe that it is important for ophthalmologists to be able to communicate effectively when breaking bad news. They found that $88 \%$ of respondents recognized that formal training would be beneficial, and $95 \%$ felt that residency was the preferred point of training. ${ }^{8}$ In another study by Hilkert et al, 34 participants (76\%) similarly agreed that ophthalmologists would benefit from a structured approach to training, and $73 \%$ felt that residency would be the ideal setting. ${ }^{9}$

In our study, a large proportion of physicians, mostly residents, had already received formal training in breaking bad news, and this experience most often occurred during medical school. In contrast, one-third of board-certified ophthalmologists in our study had never attended formal training in breaking bad news. Surprisingly, in our multivariate analysis, physicians who had received formal training had only a slightly higher perceived ability score which was not statistically significant. It is possible that the training that the physicians receive in medical school does not directly translate into ophthalmology residency or that the skills learned are not long lasting. Further information about the specific type of training that was received would be helpful to evaluate whether or not formal training would be beneficial in ophthalmology residency.

We also found that patients feel physicians do a better job than physicians feel they do themselves when breaking bad news. This could be due to the fact that communicating bad news is a stressful event that provokes anxiety in the physician, ${ }^{14,15}$ causing them to feel the interaction went more negatively than it actually did. However, whether this perceived lack of ability is real or not, feeling inadequate may also be detrimental to the physician's ability to communicate and provide emotional support to their patient when breaking bad news. ${ }^{15,16}$

The oncology literature has examined breaking bad news from the patient's perspective and highlights the importance of considering patient's preferences with regard to the manner in which bad news is delivered and the content of that message. ${ }^{17,18}$ Our study findings support this with age, race, sex, and level of education playing into patient preference of bedside manner and how they would like to receive bad news. The majority of patients in our study desired more information and stated that an informational brochure about their condition would be beneficial, something that has been shown to be true in oncology patients as well. ${ }^{19}$ While the majority of patients surveyed in our study said that they would appreciate the opportunity to speak with a technician, other staff member, or another patient with the same eye problem about their condition, the minority of physicians offered these services to their patients. Offering support services is a simple thing that physicians can do to improve the therapeutic relationship with their patients. ${ }^{19}$

It has been shown that a patient's country of origin could strongly influence whether or not they preferred others to be present when receiving bad news. In one study, $78 \%$ of Japanese patients preferred to receive bad news with family present, whereas, in another study, $81 \%$ of patients in the United States did not prefer anyone to be present when receiving bad news. ${ }^{20,21}$ We found that black patients were more likely to want their family present or to be able to speak with their family when receiving bad news. Similar to the findings by Parker et al, who surveyed 351 oncology patients, we found that women were more likely to appreciate offers of 
Breaking Bad News in Ophthalmology Fuerst et al. e89

Table 3 Univariate and multivariate analysis for factors associated with physician's ability to deliver bad news

\begin{tabular}{|c|c|c|c|c|c|}
\hline \multirow[t]{2}{*}{ Factors } & \multirow[b]{2}{*}{$N$} & \multicolumn{2}{|c|}{ Univariate analysis: Likert ability score } & \multicolumn{2}{|c|}{$\begin{array}{l}\text { Multivariate analysis }{ }^{\mathrm{a}} \text { : Likert ability } \\
\text { score }\end{array}$} \\
\hline & & Mean (SE) & $p$-Value & $\begin{array}{l}\text { Adjusted mean } \\
\text { (SE) }\end{array}$ & $p$-Value \\
\hline Age $(y)$ & & & 0.009 & & \\
\hline $20-34$ & 90 & $3.38(0.06)$ & & & \\
\hline $35-49$ & 35 & $3.40(0.10)$ & & & \\
\hline $50-64$ & 41 & $3.76(0.09)$ & & & \\
\hline$\geq 65$ & 16 & $3.63(0.15)$ & & & \\
\hline Unknown & 20 & $3.35(0.13)$ & & & \\
\hline Sex & & & 0.31 & & \\
\hline Female & 72 & $3.42(0.07)$ & & & \\
\hline Male & 130 & $3.51(0.05)$ & & & \\
\hline Race/ethnicity & & & 0.63 & & \\
\hline White & 141 & $3.47(0.05)$ & & & \\
\hline Asian & 35 & $3.43(0.10)$ & & & \\
\hline Other & 26 & $3.58(0.12)$ & & & \\
\hline $\begin{array}{l}\text { How busy are you } \\
\text { compared with } \\
\text { average U.S. } \\
\text { ophthalmologist }\end{array}$ & & & 0.051 & & \\
\hline Less busy & 40 & $3.68(0.10)$ & & & \\
\hline Same & 94 & $3.39(0.06)$ & & & \\
\hline More busy & 68 & $3.47(0.07)$ & & & \\
\hline $\begin{array}{l}\text { Current level of } \\
\text { training or } \\
\text { practice }\end{array}$ & & & $<0.001^{b}$ & & $<0.001^{b}$ \\
\hline Resident & 96 & $3.33(0.06)$ & & $3.30(0.07)$ & \\
\hline$<15 y$ & 45 & $3.44(0.09)$ & & $3.48(0.09)$ & \\
\hline$\geq 15 y$ & 61 & $3.72(0.08)$ & & $3.75(0.09)$ & \\
\hline Type of practice & & & 0.23 & & \\
\hline $\begin{array}{l}\text { Academic/ } \\
\text { University only }\end{array}$ & 185 & $3.46(0.05)$ & & & \\
\hline $\begin{array}{l}\text { Private practice } \\
\text { or mix }\end{array}$ & 17 & $3.65(0.15)$ & & & \\
\hline $\begin{array}{l}\text { Received training } \\
\text { in breaking bad } \\
\text { news }\end{array}$ & & & 0.17 & & 0.31 \\
\hline Yes & 142 & $3.44(0.05)$ & & $3.51(0.05)$ & \\
\hline No & 60 & $3.57(0.08)$ & & $3.39(0.09)$ & \\
\hline $\begin{array}{l}\text { How frequently do } \\
\text { you deliver bad } \\
\text { news to patient }\end{array}$ & & & $<0.001^{\mathrm{b}}$ & & $0.004^{b}$ \\
\hline Once per day & 31 & $3.71(0.11)$ & & $3.66(0.11)$ & \\
\hline Once per week & 80 & $3.53(0.07)$ & & $3.53(0.06)$ & \\
\hline Once per month & 74 & $3.38(0.07)$ & & $3.40(0.07)$ & \\
\hline Once per year & 17 & $3.24(0.15)$ & & $3.22(0.14)$ & \\
\hline
\end{tabular}

${ }^{\text {a } T h e ~ m u l t i v a r i a t e ~ m o d e l ~ i n c l u d e d ~ c u r r e n t ~ l e v e l ~ o f ~ t r a i n i n g ~ o r ~ p r a c t i c e, ~ f r e q u e n c y ~ o f ~ d e l i v e r i n g ~ b a d ~ n e w s, ~ a n d ~ e v e r ~ r e c e i v e d ~ t r a i n i n g ~ i n ~ b r e a k i n g ~ b a d ~}$ news.

${ }^{b}$ From test of linear trend. $p$-Values in bold are statistically significant. 
Table 4 Patient's responses on the preferred physician's bedside manner and helpful approaches when delivering bad news

\begin{tabular}{|c|c|c|c|c|c|}
\hline & $n$ & $\begin{array}{l}\text { Doctor holds my } \\
\text { hands or touches } \\
\text { my arm when } \\
\text { giving bad news }\end{array}$ & $\begin{array}{l}\text { Doctor } \\
\text { encourages me } \\
\text { to talk about my } \\
\text { feelings about } \\
\text { the bad news }\end{array}$ & $\begin{array}{l}\text { Talk with other } \\
\text { patients with } \\
\text { same eye } \\
\text { problem }\end{array}$ & Talk with family \\
\hline & & $\begin{array}{l}\text { Mean Likert } \\
\text { score (SD) }\end{array}$ & $\begin{array}{l}\text { Mean Likert } \\
\text { score (SD) }\end{array}$ & Yes (\%) & Yes (\%) \\
\hline \multicolumn{6}{|l|}{ Age $(y)$} \\
\hline $20-49$ & 34 & $2.76(0.22)$ & $3.64(0.21)$ & 17 (51.5\%) & 22 (66.7\%) \\
\hline $50-64$ & 53 & $2.88(0.17)$ & $3.60(0.16)$ & $37(74.0 \%)$ & $40(81.6 \%)$ \\
\hline$\geq 65$ & 62 & $2.89(0.16)$ & $3.57(0.15)$ & $28(46.7 \%)$ & $41(68.3 \%)$ \\
\hline$p$-Value & & 0.88 & 0.97 & 0.01 & 0.21 \\
\hline \multicolumn{6}{|l|}{ Sex } \\
\hline Female & 75 & $3.07(0.14)$ & $3.84(0.13)$ & $45(62.5 \%)$ & 55 (75.3\%) \\
\hline Male & 73 & $2.63(0.15)$ & $3.38(0.14)$ & $37(52.1 \%)$ & $48(69.6 \%)$ \\
\hline$p$-Value & & 0.04 & 0.02 & 0.21 & 0.44 \\
\hline \multicolumn{6}{|l|}{ Race } \\
\hline White & 79 & $2.47(0.14)$ & $3.29(0.13)$ & $41(52.6 \%)$ & $46(59.7 \%)$ \\
\hline Black/other & 70 & $3.29(0.14)$ & $3.94(0.14)$ & $41(63.1 \%)$ & $57(87.7 \%)$ \\
\hline$p$-Value & & $<0.001$ & $<0.001$ & 0.21 & $<0.001$ \\
\hline \multicolumn{6}{|l|}{ Education } \\
\hline High school or less & 50 & $3.10(0.18)$ & $3.86(0.17)$ & $35(71.4 \%)$ & $40(85.1 \%)$ \\
\hline Bachelor & 56 & $2.70(0.17)$ & $3.60(0.16)$ & $28(52.8 \%)$ & $35(66.0 \%)$ \\
\hline Graduate & 43 & $2.77(0.19)$ & $3.30(0.18)$ & $19(46.3 \%)$ & $28(66.7 \%)$ \\
\hline$p$-Value & & 0.23 & 0.08 & 0.04 & 0.06 \\
\hline
\end{tabular}

emotional and community support when receiving bad news. ${ }^{22}$ It is important to keep these patient preferences and cultural variations in mind when considering a training program to teach techniques in breaking bad news.

The question still remains as to the best way to implement a formal educational training program for ophthalmologists in breaking bad news. Some established protocols exist for effectively delivering bad news, perhaps the most widely known being the six-step SPIKES protocol. ${ }^{23}$ The SPIKES protocol for delivering bad news involves six stages: providing a setting for the encounter (setting), assessing the patients' perception of their condition (perception), assessing how much they want to know about their disease (invitation), providing knowledge and information to the patient (knowledge), addressing the patients' emotions (emotion), and ending with a strategy and summary (summary). In a small pilot study involving 11 ophthalmology residents at a single academic center, residents who were taught how to use the SPIKES protocol to deliver bad news had increased confidence in delivering bad news after the intervention. ${ }^{9}$ Larger studies involving more physicians and patients at multiple academic centers are needed to assess the benefit of a formal education plan.

Our findings have several implications with regard to changing the education framework to substantially improve the practice of breaking bad news in ophthalmology. Specifically, we found that more experienced physicians felt more confident in their ability to deliver bad news, but that formal training in its current form does not serve as a substitute for real-life experience. Since formal training received in medical school did not increase resident confidence in delivering bad news, but physicians and patients agree that it is a learned skill, it may be useful to have more experienced physicians model appropriate techniques for delivering bad news to help educate residents. Our findings also support the existing literature which has shown that it is important to pay attention to patient's preference when delivering bad news. We need more conscious discussion in ophthalmology about effective approaches to breaking bad news.

Our study is the largest study in ophthalmology to evaluate the abilities and associated factors on delivering bad news from both physician and patient perspectives. This study, similar to all studies based on survey data, has many limitations. The major limitation is the undeterminable response rate in this study which may introduce bias from nonresponse, inherent to survey-based studies. Physicians and/or patients who chose to take part in the survey may inherently have different views with regard to breaking bad news as compared with physicians and/or patients who chose not to take part in the survey. Self-selection bias may be involved, whereby the physicians or patients who agreed to participate perhaps had an especially positive or negative experience in breaking or receiving bad news, and thus were not representative of 
ophthalmologists as a whole or the clinic's entire patient population. It is also possible that the individuals who chose to take part in the survey may have provided biased answers in an attempt to provide what they thought the researchers wanted to find. Another limitation to our study is that we were unable to calculate the response rate of physicians or patients as we do not know how many physicians were contacted or how many patients were approached. Although we did not record the exact number of patients we approached, the majority of approached patients consented to participate. Another limitation is that the patient survey was administered at only one academic center, so the results from our patients are not necessarily generalizable. Nonetheless, the hospital chosen serves as a reasonable model for many large academic centers across the nation.

In conclusion, physicians and patients agree that delivering bad news can be learned, and our study shows that increased practice with delivering bad news leads to improved comfort and ability. Patients are less critical of their physicians' ability to deliver bad news than physicians are themselves. It is important to acknowledge that different patients have different preferences with regard to how they receive bad news and it may be beneficial to tailor delivery for certain patients. Further study is clearly indicated in the field of ophthalmology of best methods to deliver bad news that parallels successful protocols in other fields. We are hopeful that our work will reinforce the importance of good communication skills when delivering bad news in ophthalmology, help inform future ophthalmology training, and lead to strengthened physicianpatient relationships and improved patient care.

\section{Funding}

This work was supported by the National Eye Institute, Bethesda, MD (Grant no. 1RO1EY023557-01 [J.M.O.] and Award no. P30 EY001583 [G.S.Y.]) and the Department of Ophthalmology at the Perelman School of Medicine, University of Pennsylvania, Philadelphia, PA. Funds also come from the F.M. Kirby Foundation, Research to Prevent Blindness, the UPenn Hospital Board of Women Visitors, the Paul and Evanina Bell Mackall Foundation Trust, and the National Eye Institute, National Institutes of Health, Department of Health and Human Services, under eyeGENETM and contract nos. HHSN260220700001C and HHSN263201200001C. The sponsor or funding organization had no role in the design or conduct of this research.

\section{Conflict of Interest \\ None declared.}

\section{Ethical Approval \\ Ethical approval has been granted for this study.}

\section{Previous Presentations}

Association of University Professors of Ophthalmology, Annual Meeting, San Diego, CA, 2017.

\section{References}

1 National Alliance for Eye and Vision Research Fact Sheet. Available at: http://www.eyeresearch.org/resources/NEI_Factsheet.html. Accessed January 23, 2017

2 Alelwani SM, Ahmed YA. Medical training for communication of bad news: a literature review. J Educ Health Promot 2014;3:51

3 Maguire P. Breaking bad news. Eur J Surg Oncol 1998;24(03): 188-191

4 Schofield PE, Butow PN, Thompson JF, Tattersall MH, Beeney LJ, Dunn SM. Psychological responses of patients receiving a diagnosis of cancer. Ann Oncol 2003;14(01):48-56

5 Hebert HD, Butera JN, Castillo J, Mega AE. Are we training our fellows adequately in delivering bad news to patients? A survey of hematology/oncology program directors. J Palliat Med 2009;12 (12):1119-1124

6 Supiot S, Bonnaud-Antignac A. Using simulated interviews to teach junior medical students to disclose the diagnosis of cancer. J Cancer Educ 2008;23(02):102-107

7 Zhou Q, Shen JC, Liu YZ, Lin GZ, Dong H, Li K. Effects of doctorpatient communication on quality of life among breast cancer patients in southern China. Asian Pac J Cancer Prev 2014;15(14): 5639-5644

8 Zakrzewski PA, Ho AL, Braga-Mele R. Should ophthalmologists receive communication skills training in breaking bad news? Can J Ophthalmol 2008;43(04):419-424

9 Hilkert SM, Cebulla CM, Jain SG, Pfeil SA, Benes SC, Robbins SL. Breaking bad news: A communication competency for ophthalmology training programs. Surv Ophthalmol 2016;61(06):791-798

10 Mack JW, Hilden JM, Watterson J, et al. Parent and physician perspectives on quality of care at the end of life in children with cancer. J Clin Oncol 2005;23(36):9155-9161

11 Lee AG, Arnold AC. The next accreditation system in ophthalmology. Surv Ophthalmol 2015;60(01):82-85

12 Morse AR. Talking to patients about vision loss and rehabilitation. Arch Ophthalmol 2012;130(02):235-237

13 Orgel E, McCarter R, Jacobs S. A failing medical educational model: a self-assessment by physicians at all levels of training of ability and comfort to deliver bad news. J Palliat Med 2010;13(06):677-683

14 Buckman R. Breaking bad news: why is it still so difficult? Br Med J (Clin Res Ed) 1984;288(6430):1597-1599

15 Ptacek JT, Fries EA, Eberhardt TL, Ptacek JJ. Breaking bad news to patients: physicians' perceptions of the process. Support Care Cancer 1999;7(03):113-120

16 Ptacek JT, Eberhardt TL. Breaking bad news. A review of the literature. JAMA 1996;276(06):496-502

17 Dosanjh S, Barnes J, Bhandari M. Barriers to breaking bad news among medical and surgical residents. Med Educ 2001;35(03): 197-205

18 Maguire P, Fairbairn S, Fletcher C. Consultation skills of young doctors: II-Most young doctors are bad at giving information. $\mathrm{Br}$ Med J (Clin Res Ed) 1986;292(6535):1576-1578

19 Randall TC, Wearn AM. Receiving bad news: patients with haematological cancer reflect upon their experience. Palliat Med 2005;19(08):594-601

20 Fujimori M, Akechi T, Morita T, et al. Preferences of cancer patients regarding the disclosure of bad news. Psychooncology 2007;16 (06):573-581

21 Kim MK, Alvi A. Breaking the bad news of cancer: the patient's perspective. Laryngoscope 1999;109(7, Pt 1):1064-1067

22 Parker PA, Baile WF, de Moor C, Lenzi R, Kudelka AP, Cohen L. Breaking bad news about cancer: patients' preferences for communication. J Clin Oncol 2001;19(07):2049-2056

23 Baile WF, Buckman R, Lenzi R, Glober G, Beale EA, Kudelka AP. SPIKES-A six-step protocol for delivering bad news: application to the patient with cancer. Oncologist 2000;5(04):302-311 